\title{
Piscivorous fish patrol krill swarms
}

\author{
Stein Kaartvedt ${ }^{1, *}$, Anders Røstad ${ }^{1}$, Øyvind Fiksen ${ }^{2}$, Webjørn Melle ${ }^{3}$, \\ Thomas Torgersen ${ }^{2}$, Mari Tiseth Breien ${ }^{3}$, Thor A. Klevjer ${ }^{1}$ \\ ${ }^{1}$ Department of Biology, University of Oslo, PO Box 1066 Blindern, 0316 Oslo, Norway \\ ${ }^{2}$ Department of Biology, University of Bergen, PO Box 7800, 5020 Bergen, Norway \\ ${ }^{3}$ Institute of Marine Research, PO Box 1870, 5817 Bergen, Norway
}

ABSTRACT: Dense swarms of the krill Meganyctiphanes norvegica in the Norwegian Sea were patrolled by large, piscivorous fish, which apparently use the krill swarms as feeding grounds in their hunt for planktivores. For the krill, patrols of piscivores may add to the generally accepted anti-predator benefit of the swarming behavior. The fact that krill swarms govern small-scale patchiness of large piscivores emphasizes the key role of krill in oceanic ecosystems.

KEY WORDS: Swarms · Fish · Anti-predator benefits · Behavioral cascades $\cdot$ Meganyctiphanes norvegica

Resale or republication not permitted without written consent of the publisher

\section{INTRODUCTION}

Many species of krill form social aggregations (swarms and schools). This behavior affects reproduction, feeding, energy consumption and interactions with predators (Ritz 1994, 2000). The major benefit of swarming is generally presumed to be protection from predation, mainly derived from evasion and dilution factors once an attack is launched (e.g. O'Brien \& Ritz 1988). However, swarms may also attract and make krill vulnerable to predators capable of exploiting such dense concentrations (Nicol \& O'Dor 1985, Ritz 1994). In this note we report a novel observation of recurrent associations between krill swarms and large piscivorous fish in the northern Norwegian Sea. We suggest that piscivores use krill swarms as feeding grounds in their hunt for planktivores attracted by the swarms. For the individual krill, such patrols of large piscivores would add to the generally accepted anti-predator benefit provided by the swarming behavior.

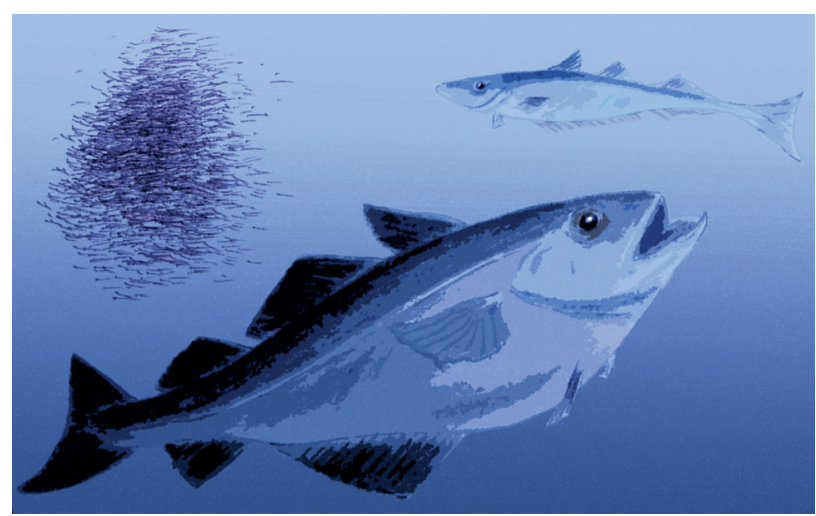

Swarms of krill patrolled by large piscivorous fish. The piscivores prey on planktivores attracted by the swarms, at the same time providing protection for the krill.

Illustration by Hege Vestheim

\section{MATERIALS AND METHODS}

The studies were carried out during a research cruise with RV 'G.O. Sars', which had mainly been allocated the task of assessing herring in the Norwegian Sea. The results reported here were collected on 24-25 May 2004 at a site that appeared to be particularly rich in krill and fish $\left(\sim 70^{\circ} \mathrm{N}, 4^{\circ} \mathrm{E}\right)$. We applied SIMRAD EK 60 echo sounders at 5 frequencies $(18,38$, 70,120 , and $200 \mathrm{kHz}$; settings in Table 1). The beam width of the transducers was $7^{\circ}$, except for the $18 \mathrm{kHz}$ transducer, which had a beam width of $12^{\circ}$. Postprocessing of data was done by the Sonar 5 Pro- (Balk \& Lindem 2002) and Sonar 6-MP software, and echograms were visualized in Matlab.

Acoustic targets were captured by a pelagic trawl with a vertical opening of $\sim 30 \mathrm{~m}$ (a so-called Åkra 
Table 1. Echo sounders and settings

\begin{tabular}{|ll|}
\hline Technical specifications/settings & \\
Frequency $(\mathrm{kHz})$ & $18,38,70,120,200$ \\
Ping rate $\left(\mathrm{s}^{-1}\right)$ & 1.45 \\
$3 \mathrm{~dB}$ beam width $\left(^{\circ}\right)$ & $7^{\circ}\left(12^{\circ}\right.$ at $\left.18 \mathrm{kHz}\right)$ \\
Pulse length $(\mathrm{ms})$ & 1.024 \\
Depth resolution $(\mathrm{m})$ & 0.189 \\
Range $(\mathrm{m})$ & 500 \\
Target detection parameters & \\
Min. echo length & 0.8 \\
Max. echo length & 1.4 \\
Max. phase deviation & 2.0 \\
Max. gain compensation $(\mathrm{dB})$ & 6.0 \\
\hline
\end{tabular}

trawl). The mesh sizes ranged from $3200 \mathrm{~mm}$ in the front to $20 \mathrm{~mm}$ in the cod end. Scanmar depth sensors were used to monitor depth, and a SIMRAD trawl eye monitored the flow of catch into the trawl during sampling. The acoustic size distribution of fish was assessed in 2 ways. Split-beam echo sounders enable in situ measurements of target strength (TS) for individual fish, which is a function of fish size (Ehrenberg \& Torkelson 1996). TS measurements were done at long range. Therefore, strict criteria were used to avoid multiple targets (Table 1). Results included here are based on manually tracked individuals that could be clearly seen as separate targets. This procedure reduced sample size in the analysis. Additionally, we assessed size distribution by visually examining $40 \mathrm{log}$ $\mathrm{R}$ echograms, where the colors (strength) of individual targets are independent of range (results not shown).

The acoustic records revealed swarms with progressively stronger backscatter with increasing frequency up to $120 \mathrm{kHz}$ (Fig. 1). This frequency response is similar to that of krill (Greene et al. 1991), and the swarms were ascribed to krill. Strong targets occurred just beneath the swarms (see 'Results and discussion'). MacLennan \& Simmonds (1992) cautioned that diffuse 'ragged tails' below fish schools were the result of multiple scattering from the school rather than echoes from associated fish. This explanation can be rejected for our results, since the frequency response for the 'tail' was the inverse for that of the swarms (Fig. 1). At the lowest frequency the swarm itself virtually disappeared, while the targets below became stronger.

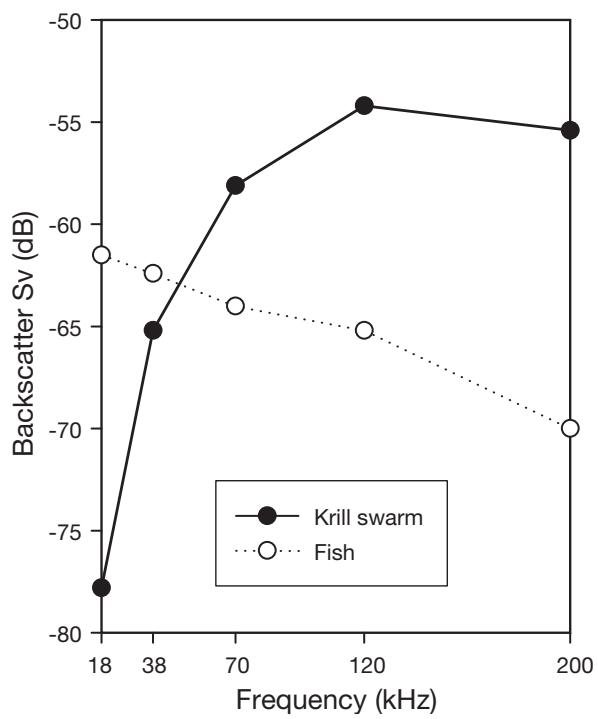

Fig. 1. Acoustic backscatter at 18, 38, 70, 120 and $200 \mathrm{kHz}$ from a representative section of a swarm (solid line) and the 'tail' of targets beneath a swarm (stippled line). Sv: volume backscattering strength

The numerical density in the swarms was assessed based on the total acoustic backscatter at $120 \mathrm{kHz}$ (volume backscattering strength [Sv], on average $-55 \mathrm{db}$ ), the size of the swarming krill (average length of $26 \mathrm{~mm}$; trawl catch) and literature values relating strength of individual echoes (TS) to size (Greene et al. 1991). Krill swarms normally consist of equally sized individuals (Hamner \& Hamner 2000). In the acoustic abundance estimate, we therefore used the krill size from the catch, even though the coarse meshed gear would select against the smallest individuals. In assessing total swarm size, it was assumed (based on the acoustic records) that the swarms were oblate spherical in shape, with $50 \mathrm{~m}$ vertical and $120 \mathrm{~m}$ horizontal extensions.

\section{RESULTS AND DISCUSSION}

The acoustic studies revealed swarms of krill that were located between 100 and $200 \mathrm{~m}$ depth both during the day and the light summer night at $70^{\circ} \mathrm{N}$ (Figs. 2 \& 3). The trawl was too coarse to capture the

Fig. 2. Acoustic records of krill swarms and associated fish from the Norwegian Sea $\left(\sim 70^{\circ} \mathrm{N}, 4^{\circ} \mathrm{E}\right)$ during the day on 24 May 2004. (a) $120 \mathrm{kHz}$. (b,c) Expanded sections at $18 \mathrm{kHz}$, displaying individual fish associated with swarms. Color scale refers to echo intensity (Sv), with grey showing the weakest and reddish-brown the strongest echoes. Krill swarms are strong targets at $120 \mathrm{kHz}$, and almost invisible at $18 \mathrm{kHz}$, while fish are seen at both frequencies. Mainly large fish were associated with the swarm in (b), while a mixture of fish sizes were found below the swarm in (c). The strong, red targets are ascribed to saithe, while the weaker, greenish targets are ascribed to blue whiting. The red line in (c) outlines the swarm size as measured at $120 \mathrm{kHz}$. The ship moved at $\sim 4$ knots, and 5 swarms are displayed from this 30 min recording period. Time is UTC 


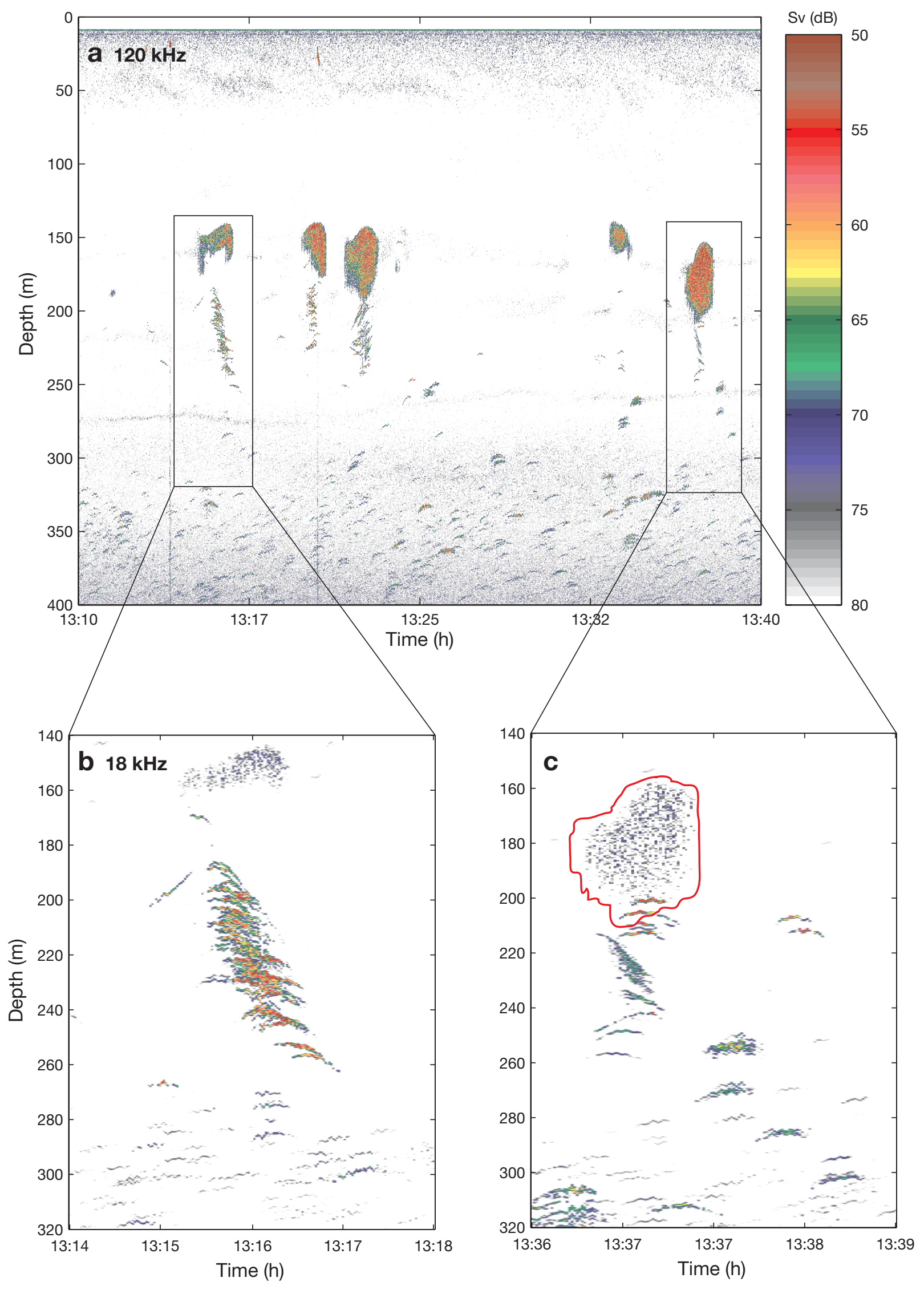




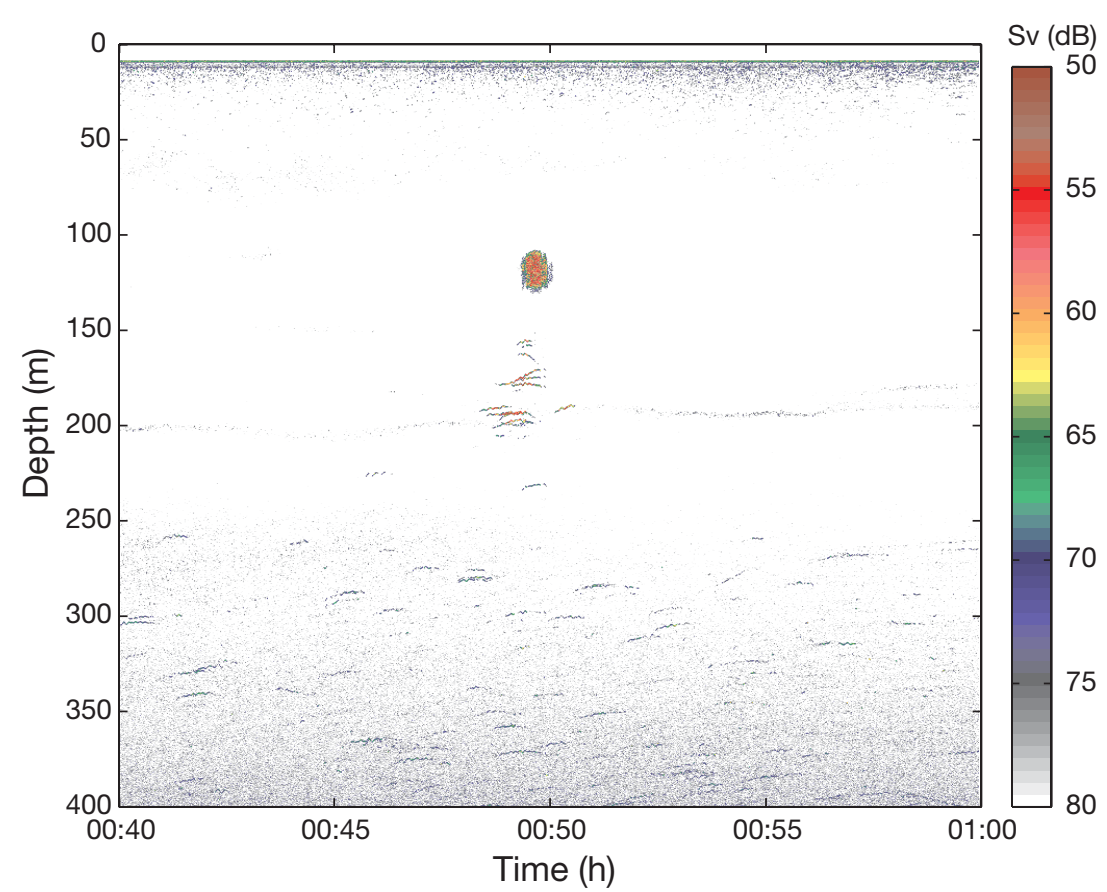

Fig. 3. Acoustic records at $120 \mathrm{kHz}$ of a krill swarm and associated fish at night on 25 May $2004\left(\sim 70^{\circ} \mathrm{N}, 4^{\circ} \mathrm{E}\right)$. The swarm was virtually invisible at $18 \mathrm{kHz}$ (not shown). Color scale refers to echo intensity (Sv), with grey showing the weakest and reddish-brown the strongest echoes. The red targets just beneath the swarm are ascribed to saithe. The fish echoes below $\sim 250 \mathrm{~m}$ are ascribed to blue whiting. The ship moved at $\sim 2.5$ knots during the recording period. Time is UTC

krill quantitatively. Nevertheless, a catch of several kg of $26 \mathrm{~mm}$ long Meganytiphanes norvegica was made when targeting 1 of the swarms. Capture of krill from this swarm was documented by the trawl eye during sampling. We roughly estimated the volume of a typical swarm at $\sim 380000 \mathrm{~m}^{3}$, and numerical densities at $\sim 200$ ind. $\mathrm{m}^{-3}$, suggesting a total biomass of $\sim 11 \mathrm{t}$ per swarm.

Underneath most swarms was a 'stack' of fish that could extend almost $100 \mathrm{~m}$ below the krill (Figs. 2 \& 3). Some individuals were also located inside, or close to the swarms (Fig. 2). Surprisingly, the strength of the acoustic echoes suggested that these fish commonly (but not exclusively) were large piscivores rather than smaller planktivores. Two trawl tows between 200 and $300 \mathrm{~m}$ depth captured four 6 to $10 \mathrm{~kg}(60$ to $110 \mathrm{~cm})$ large saithe Pollachius virens, which was the only fish likely to be the source of these strong echoes. The median and mean TS at $38 \mathrm{kHz}$ of the large, individual fish (red echoes) displayed in Fig. $2 \mathrm{~b}$ and $\mathrm{c}$ and Fig 3, were -24.3 and $-24.5 \mathrm{~dB}$ respectively $(\mathrm{n}=12)$, which would correspond to saithe $>1 \mathrm{~m}$ (Foote et al. 1986). Note that saithe of this size is inherently difficult to capture with an Åkra trawl.

Large saithe will normally forage as piscivores (Bergstad 1991), and saithe captured in the trawl had fish and the cephalopod Gonatus sp. in their stom- achs. Apparently, the saithe preyed on planktivores attracted by the krill, rather than on the krill itself. While some large fish lurked inside, or close to the swarms, piscivores located under the krill swarms would spot planktivores feeding on the krill, or planktivores ascending towards the swarms from deeper layers. Prey is most efficiently detected in the contrast of downwelling light (Tethmeyer \& Kils 1995, Warrant \& Locket 2004). The dense swarms of the partly transparent krill would generate a shadow, and a weak collective silhouette may actually be favorable for spotting fish prey from below whilst simultaneously keeping their position under the krill swarm (E. J. Warrant pers. comm.).

Blue whiting Micromesistius poutassou were the most likely deep-living predators on krill and prey for saithe. They constituted an acoustic layer below 250 to $300 \mathrm{~m}$, and around $25 \mathrm{~cm}$ long blue whiting was by far the dominant fish in trawl catches from this depth. Some more shallowly distributed blue whiting were recorded near the swarms (Fig. 2). The TS of fish in these groups were -40 to $-35 \mathrm{~dB}$, which would correspond to blue whiting of 16 to $30 \mathrm{~cm}$ (Forbes 1985; cited in MacLennan \& Simmonds 1992). Krill is the main food item of blue whiting in the Norwegian Sea (Timokhina 1974). The acoustic records otherwise showed schools of herring Clupea harengus, occurring both in mid-water and near the surface. Trawling near the surface only caught herring foraging on copepods.

We argue that in a seemingly homogenous habitat, predator-prey interactions at several trophic levels were concentrated in small hot-spots. The physical presence of swarming krill appears to alter the behavior and prey consumption of piscivores, and thereby the predation risk to the foraging planktivores. This fits within the notion of behaviorally mediated indirect interactions (Dill et al. 2003, Fiksen et al. 2005). Such behavioral cascades have previously received little attention in marine ecosystems. This is probably caused by a lack of appropriate observation methods, and not because behavioral cascades are of lesser importance compared to other ecosystems (Dill et al. 2003). The acoustic methods used in our study enabled observation and visualization of the oceanic interior. The fact that krill swarms govern small-scale patchiness of large piscivores emphasizes the key role of krill in oceanic ecosystems. 
For the individual krill, patrols of large piscivores would add to the anti-predator benefit of the swarming behavior ('the enemy of my enemy is my friend'). Saithe may benefit from the stronger aggregation and higher exposure of its planktivore prey. If our interpretations are correct, then the losers in the game are the planktivores, which will suffer from higher predation risk when foraging on prey patrolled by predators. Whether consumption and repelling of planktivores by piscivores may in fact be instrumental in encouraging swarming behavior of krill remains to be investigated.

Acknowledgements. This study was funded by the Research Council of Norway.

\section{LITERATURE CITED}

Balk H, Lindem T (2002) Sonar4 and Sonar5-Pro Post processing systems. Operator manual. Lindem Data Acquisition, Oslo

Bergstad OA (1991) Distribution and trophic ecology of some gadoid fish of the Norwegian Deep. 1. Accounts of individual species. Sarsia 75:269-313

Dill LM, Heithaus MR, Walters CJ (2003) Behaviorally mediated indirect interactions in marine communities and their conservation implications. Ecology 84:1151-1157

Ehrenberg JE, Torkelson TC (1996) Application of dual-beam and split-beam target tracking in fisheries acoustics. ICES J Mar Sci 53:329-334

Fiksen Ø, Eliassen S, Titelman J (2005) Multiple predators in

Editorial responsibility: Otto Kinne (Editor-in-Chief),

Oldendorf/Luhe, Germany the pelagic: modelling behavioural cascades. J Anim Ecol 74:423-429

Foote KG, Aglen A, Nakken O (1986) Measurement of fish target strength with a split-beam echo sounder. J Acoust Soc Am 80:612-621

Forbes ST (1985) Progress in dual-beam target-strength measurements on herring and blue whiting. Int Counc Explor Sea CM 1985/B:22

Greene CH, Stanton TK, Wiebe PH, McClatchie S (1991) Acoustic estimates of Antarctic krill. Nature 349:110

Hamner WM, Hamner PP (2000) Behaviour of Antarctic krill (Euphausia superba): schooling, foraging, and antipredatory behaviour. Can J Fish Aquat Sci 57(Suppl 3):192-202

MacLennan DN, Simmonds EJ (1992) Fisheries acoustics. Chapman \& Hall, London

Nicol S, O'Dor RK (1985) Predatory behaviour of squid (Illex illecebrosus) feeding on surface swarms of euphausiids. Can J Zool 63:15-17

O'Brien DP, Ritz DA (1988) Escape responses of gregarious mysids (Crustacea: Mysidacea): towards a general classification of escape responses in aggregated crustaceans. J Exp Mar Biol Ecol 116:257-272

Ritz DA (1994) Social aggregation in pelagic invertebrates. Adv Mar Biol 30:156-216

Ritz DA (2000) Is social aggregation in aquatic crustaceans a strategy to conserve energy? Can J Fish Aquat Sci 57(Suppl 3):59-67

Tethmeyer H, Kils U (1995) To see and not be seen: the visibility of predator and prey with respect to feeding behaviour. Mar Ecol Prog Ser 126:1-8

Timokhina AF (1974) Feeding and daily food consumption of the blue whiting (Micromesistius poutassou) in the Norwegian Sea. J Ichtyol 14:760-765

Warrant EJ, Locket NA (2004) Vision in the deep sea. Biol Rev $79: 671-712$

Submitted: January 4, 2005; Accepted: June 7, 2005

Proofs received from author(s): July 25, 2005 